\title{
Functional analysis of the sporulation-specific SPR6 gene of Saccharomyces cerevisiae
}

\author{
L. A. Kallal ${ }^{1}$, M. Bhattacharyya ${ }^{3 *}$, S. N. Grove ${ }^{2}$, R. F. Iannacone ${ }^{3}$, T. A. Pugh ${ }^{3 * *}$, D. A. Primerano ${ }^{4}$, \\ and M. J. Clancy ${ }^{1}$ \\ 1 Department of Biological Sciences, University of New Orleans, New Orleans, LA 70148, USA \\ 2 Department of Biology, Goshen College, Goshen, IN 46526, USA \\ 3 Department of Biological Sciences, University of Notre Dame, Notre Dame, IN 46556, USA \\ ${ }^{4}$ Department of Microbiology, Marshall University School of Medicine, Huntington, WV 25755, USA
}

Received May 15/July 12, 1990

\begin{abstract}
Summary. The SPR6 gene of Saccharomyces cerevisiae encodes a moderately abundant RNA that is present at high levels only during sporulation. The gene contains a long open reading frame that could encode a hydrophilic protein approximately $21 \mathrm{kDa}$ in size. This protein is probably produced by the yeast, because the lac $Z$ gene of Escherichia coli is expressed during sporulation when fused to $S P R 6$ in the expected reading frame. $S P R 6$ is inessential for sporulation; mutants that lack SPR6 activity sporulate normally and produce viable ascospores. Nonetheless, the SPR6 gene encodes a function that is relevant to sporulating cells; the wild-type allele can enhance sporulation in strains that are defective for several $S P R$ functions. SPR6 is located on chromosome V, 14.4 centimorgans centromere-distal to MET6.
\end{abstract}

Key words: Saccharomyces cerevisiae - Sporulation Inessential genes - Genome organization

\section{Introduction}

Numerous genes are expressed exclusively, or at greatly elevated levels, during the sporulation phase of the Saccharomyces cerevisiae life cycle. The majority of these sporulation-regulated genes were identified by the higher abundance of the corresponding transcripts in sporulating cells compared to control populations of cells. Such differential screening methods, employed by several laboratories, have revealed at least 40 different genes whose transcripts appear at a variety of times during sporulation (Clancy et al. 1983; Percival-Smith and Segall 1984; Gottlin-Ninfa and Kaback 1986).

\footnotetext{
* Present address: Department of Biology, Washington University, Saint Louis, MO 63110, USA

** Present address: Department of Biology, University of Michigan, Ann Arbor, MI 48108, USA
}

Offprint requests to: $\mathrm{M}$. J. Clancy
Of the sporulation-specific genes identified by differential hybridization, only one (SPS1; Percival-Smith and Segall 1986) has been shown to be essential to the sporulation process. A large group of additional genes are not essential, although several have discernible functions (e.g., SPS100; Law and Segall 1988) and others encode highly abundant transcripts. The appearance of the latter is tightly coupled to the sporulation process (SPR3, SPR1; Holaway et al. 1987; Kao et al. 1989). Other inessential genes include SPR1, SPR2, SPS2, SPR 9 , SPS4, SPS100, SGA1, LGN1, LGN2, and LGN3 (Yamashita and Fukui 1985; Garber and Segall 1986; Gottlin-Ninfa and Kaback 1986; Kao et al. 1989; Primerano, Muthukumar, Suhng and Magee, submitted).

Thus, the majority of sporulation-induced yeast genes appear to encode regulated, but inessential, functions. This is not surprising, in view of several recent studies using gene disruption and R-looping techniques to estimate the fraction of the yeast genome that is essential for viability. In one case, a study of $41 \mathrm{~kb}$ of contiguous DNA from chromosome I revealed 15 transcription units in a region previously thought to contain only three essential genes (Kaback et al. 1984; Coleman et al. 1986; Steensma et al. 1987). In another case, examination of genomic clones from random locations estimated that less than $30 \%$ of the genome is essential, although $80 \%$ is transcribed (Goebl and Petes 1986). In this respect, sporulation-specific transcription units resemble their vegetative counterparts; the average gene which is expressed during sporulation is not required for the process to occur.

Several explanations have been offered for the apparent excess of genetic information in yeast. One is that some inessential genes reflect an evolutionary vestige of previously needed functions; if so, they are not maintained by selection and are presently in the process of decay. Another is that the genome encodes numerous redundant or reiterated functions, as it is known to do for several gene families, including heat shock proteins (Lindquist and Craig 1988), histones (Osley and Hereford 1981) and others. Still other inessential genes could 
provide helpful functions which are maintained by selection because of the advantage they provide the cell.

In an effort to understand which of these possibilities describes the "late" sporulation-specific genes, we have examined one of these in detail. The transcript of SPR 6 appears in sporulating cells at the time of meiosis I and persists throughout meiosis and spore formation. This gene, like others of its class, encodes a moderately abundant transcript that is undetectable in vegetatively growing cells (Holaway et al. 1985). Our results demonstrate that SPR6 contains many of the hallmarks of a functional yeast gene, including a long open reading frame that is flanked by appropriately placed transcription and translation start signals. We also show that a fusion between this open reading frame and the lac $Z$ gene of $E s-$ cherichia coli is translated in vivo during sporulation.

To explore the possibility that SPR6 might perform a function which is helpful for sporulation, we have used gene disruption techniques to construct strains which lack $S P R 6$ function, either solely or in combination with other $S P R$ null mutations. We show that reduced activity of the late genes leads to a reduction in the efficiency of sporulation that can be complemented by the reintroduction of the wild-type alleles. This suggests that $S P R 6$ and the other late genes encode functional products which perform helpful roles in sporulation. These results lead us to conclude that the late sporulation genes are maintained in yeast as a result of these roles.

\section{Materials and methods}

Isotopes. $\left[\alpha^{32} \mathrm{P}\right]-\mathrm{dCTP},\left[\alpha^{32} \mathrm{P}\right]-\mathrm{dATP}$ and $\left[\gamma^{32} \mathrm{P}\right]$-ATP were from ICN (Costa Mesa, Calif.).

Chemicals and enzymes. General molecular biology reagents (agarose, acrylamide, formamide, $\mathrm{CsCl}$ ) and most enzymes were from Bethesda Research Laboratories (Gaithersburg, Md.). DNA ligase and some restriction enzymes were from New England Biolabs (Beverly, Mass.). Reagents for sequencing experiments using the Klenow fragment of DNA polymerase I were from Bethesda Research Laboratories and those for experiments using "Sequenase" were from United States Biochemical Corporation (Cleveland, Ohio), Reagents for construction of nested deletions were provided by the CYCLONE kit from International Biotechnologies Inc (New Haven, Ct.). General chemicals were from Sigma (St Louis, Mo.).

Construction and manipulation of Saccharomyces cerevisiae strains. Yeast growth and sporulation were accomplished as described previously (Holaway et al. 1985) using YEPD, YEPA or PSP and SPM supplemented as appropriate for the strain (Sherman et al, 1981); PSP contained $0.67 \%$ yeast nitrogen base, $0.1 \%$ yeast extract, $1.0 \%$ potassium acetate and $50 \mathrm{mM}$ potassium phthalate buffered to pH 5.1, and was supplemented as appropriate to the strain. Cells to be sporulated were pregrown in YEPA or PSP to a cell density of approximately $4 \times 10^{7}$ cells per $\mathrm{ml}$ of culture, as determined by counting an aliquot of the culture using a hemocytometer. Cells were removed from the spent vegetative growth medium by centrifugation for $5 \mathrm{~min}$ at the highest setting of a clinical centrifuge. They were then washed once with a volume of sterile distilled water equal to the original culture volume, and once with SPM. The cells were then resuspended in SPM at a final concentration of $2 \times 10^{7}$ cells per $\mathrm{ml}$. The cells were returned to a fresh tube or erlenmeyer flask that was at least ten-fold larger in volume than the sporulating culture, and were incubated with shaking at $30^{\circ} \mathrm{C}$ in a Brunswick
G-76 shaking water bath. The final percentage of sporulated cells was determined after $48-72 \mathrm{~h}$ of incubation, as indicated in the legends to the individual figures. Progress through sporulation was monitored by direct microscopic observation using a hemocytometer, as above, or with the fluorescent stain DAPI $\left(4^{\prime}, 6\right.$-diamidino-2phenylindole; Williamson and Fennel 1975) using a Nikon Labophot microscope equipped for fluorescence. Transformation was accomplished by incubating yeast cells with DNA in the presence of lithium ions and polyethylene glycol (PEG) as descsribed by Ito et al. (1983). Gene replacements were accomplished by transforming diploid strains with plasmid DNAs that had been digested with restriction enzymes to target integration of the desired disrupted alleles to their homologous chromosomal loci according to the method of Rothstein (1983). SPR6 disruptions were obtained from pLK3 DNA (see below) using digestion of the plasmid with EcoRI and selection for the HIS3 marker within the SPR6 coding sequences. $S P R 1$ and $S P R 3$ were disrupted likewise, by digestion of pSPR3 CCla:LEU2 and pSLEU2-1 with HindIII (for SPR3) or a combination of $B a m H I$ and DraI (for SPR1). The expected structures of the disrupted alleles were verified by hybridization analysis (Southern 1975) of restriction-digested DNAs from the prototrophic transformants. The strains used in this study are listed in Table 1. Genetic manipulations were carried out by the standard methods described by Sherman et al. (1981). All Saccharomyces cerevisiae strains used to analyze the functions of the $S P R$ genes were derivtives of DK337 (Gottlin-Ninfa and Kaback 1986; kindly provided by David Kaback). Singly disrupted strains were obtained as haploid segregants of a derivative of DK337 that had been diploidized with HO (Russell et al. 1986; kindly provided by Ira Herskowitz). The diploid was transformed with appropriately cut plasmid DNAs as above and haploid $\mathrm{Leu}^{+}$or $\mathrm{His}^{+}$segregants obtained. Strains that were disrupted for SPR6 in combination with either $S P R 1$ or $S P R 3$ were obtained as $\mathrm{His}^{+} \mathrm{Leu}^{+}$segregants from crosses of the appropriate haploids. Strains that were lacking both $S P R 1$ and $S P R 3$ were made by crossing singly disrupted haploids and obtaining Leu ${ }^{+}$segregants from tetrads in which leucine prototrophy had segregated $2: 2$. Since the two $L E U 2$ alleles had segregated to the same spores in such tetrads, these haploids would necessarily contain both spr 1:LEU2 and spr $3: L E U 2$ disruptions. Triply disrupted strains were obtained similarly, from a cross between a haploid that was spr1:LEU2 spr3:LEU2 and a second haploid of genotype spr6:HIS3; Leu ${ }^{+} \mathrm{His}^{+}$segregants from the appropriate tetrads were chosen for analysis. The diploid (YLK1396) that was formed by mating the above haploids was heterozygous for all three gene disruptions and was retained for use as a wild-type control. Diploids were obtained by transforming the desired segregants with $\mathrm{HO}$ as above.

Mapping experiments. SPR6 was assigned to chromosome V using Beckman's GenLine ${ }^{\mathrm{TM}}$ TAFE (transverse alternating field electrophoresis) system as directed by the manufacturer, using commercially available $S$. cerevisiae chromosome standards (Beckman, Fullerton, CA). Strains containing chromosome V markers were constructed using Cold Spring Harbor Yeast Course strains D665-1A and SL183-21C, Yeast Genetics Stock Center strains XJB3-1D and XJB3-1B and haploid derivatives of DK 337. SPR6 was followed in crosses using the HIS3 gene integrated at the SPR6 locus. The final strain used to map spr6: HIS3 was YLKMS-6 (Table 1).

Escherichia coli and bacteriophage strains. E. coli strains used for the propagation of plasmids and phage $\lambda$ were TG1, DH $5 \alpha$ (Bethesda Research Laboratories) and KH802 (Maniatis et al. 1982). Cells were maintained in LB medium (Maniatis et al. 1982) and transformed using the calcium chloride method described by Maniatis et al. (1982) or by the method of Hanahan (1983). Bacteriophage $\lambda$ strains were propagated using E. coli $\mathrm{KH} 802$ and were grown and maintained in NZCYM and SM, respectively (Maniatis et al. 1982). M13 phage were grown and maintained on JM107 or JM109 as recommended by Messing (1983), using M9 minimal salts medium (Miller 1972) supplemented with X-gal [5-bromo-4-chloro-3-indoyl(3-D-galactoside)] and IPTG (isopropyl- $\beta$-D-thiogalactoside). 
Table 1. Strains used in this study

\begin{tabular}{|c|c|}
\hline Mapp & \\
\hline $\begin{array}{l}\text { D665-1A } \\
\text { SL183-21C } \\
\text { XJB3-1D } \\
\text { XJB3-1B }\end{array}$ & 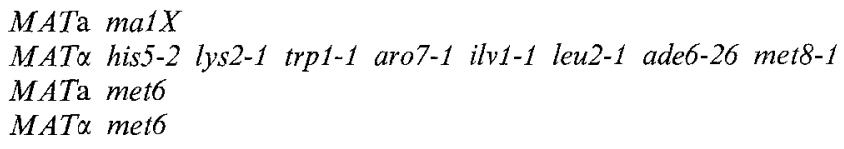 \\
\hline YLKMS-6 & 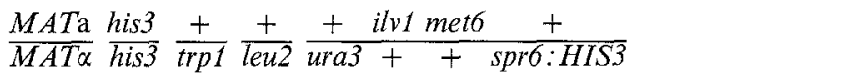 \\
\hline
\end{tabular}

Disruption strains:

DK337 MATa leu2 trp1 his3 ura3 ade1 + SPR1 SPR3 SPR6

$\overline{M A T \alpha} \overline{\text { leu2 }} \frac{\text { trp1 }}{\text { his3 }} \frac{1}{+} \frac{\text { t }}{\text { ade2 }} \overline{\text { SPR1 }} \overline{\text { SPR3 }} \overline{\text { SPR6 }}$

YLK1396

$\frac{M A T \mathrm{a}}{M A T \alpha} \frac{\text { leu2 }}{\text { leu2 }} \frac{\operatorname{trp1}}{\operatorname{trp1} 1} \frac{\text { his3 }}{\text { his3 }} \frac{\text { ura3 }}{\text { ura3 }} \frac{\operatorname{spr} 1: L E U 2}{+} \frac{\text { spr3:LEU2 }}{+} \frac{+}{\text { spr6:HIS3 }}$

YLK6

MATa leu2 trp1 his3 ura3 SPR1 SPR3 spr6:HIS3

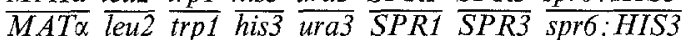

YLK1335-3

MATa leu2 trp1 his3 ura3 spr1:LEU2 spr3:LEU2 SPR6 $\overline{M A T \alpha} \frac{1 \text { leu2 }}{\operatorname{trp} 1} \frac{15}{\text { his3 }} \frac{\text { ura3 }}{\text { spr1:LEU2 }} \frac{\text { spr3:LEU2 }}{\text { SPR6 }}$

YLK16-9a

MATa leu2 trp1 his3 ura3 spr1:LEU2 SPR3 spr6:HIS3

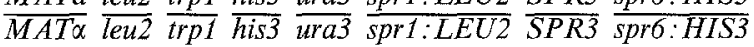

YLK36-1a

MATa leu2 trp1 his3 ura3 SPR1 spr3:LEU2 spr6:HIS3 $\overline{M A T \alpha} \frac{1}{\text { leu2 } 2} \frac{\text { trpq }}{\text { his3 } 3} \frac{\text { ura3 }}{\text { SPR1 }} \frac{\text { spr3:LEU2 }}{\text { spro:HIS3 }}$

YLK984 MATa leu2 trp1 his3 ura3 spr1:LEU2 SPR3:LEU2 spr6:HIS3

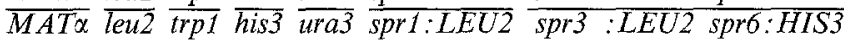

YLK9820 MATa leu2 trp1 his3 ura3 spr1:LEU2 spr3:LEU2 spr6:HIS3 $\overline{M A T \alpha} \overline{\text { leu2 }} \frac{\text { trp1 }}{\text { his3 }} \overline{\text { ura3 }} \frac{\text { spr1:LEU2 }}{\text { spr3:LEU2 }} \frac{\text { spr6:HIS3 }}{\text { sprithe }}$

Strains for assaying $\beta$-galactosidase activity:

GKY5

MATa HO leu2 trp1 his3 ura3

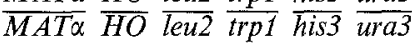

GK25

MATa ho:HIS3 leu2 trp1 his3 ura3

GK31

MAT $\alpha$ ho:HIS3 leu2 trp1 his3 ura3

Plasmids. pRI1 was constructed by subcloning a $6.4 \mathrm{~kb} E c o$ RI fragment containing sporulation-regulated sequences from $\lambda$ sp41 (Clancy et al. 1983) into the EcoRI site of pBR322. Genomic disruptions of SPR6 were accomplished using pLK3, a derivative of $\mathrm{pRI} 1$ in which a $2.1 \mathrm{~kb} B s t$ EII fragment had been replaced by the HIS3 gene. pLK 3 was constructed by first deleting the unique BamHI site in the pBR322 backbone of pRI1, and replacing a $2.1 \mathrm{~kb}$ Bst EII fragment with a BamHI linker. HIS3 was then isolated as a $1.6 \mathrm{~kb}$ BamHI fragment (Rothstein 1983; kindly provided by David Kaback) and cloned into this site. YCp50-SPR6 contained a wild-type allele of SPR6 cloned as an XhoI-EcoRI fragment between the unique $E c o$ RI and $S a l$ I sites of YCp50 (Boeke et al. 1985). pSLEU21 contained a disrupted allele of $S P R 1$. It was constructed by replacing the DNA between the unique $S a l$ I and $S s t I$ sites within the gene with a $3.0 \mathrm{~kb} X h o I-S_{s t} \mathrm{I}$ fragment containing $L E U 2$. The source of the LEU2 fragment was YEp13 (Broach et al. 1979). The wild-type SPR3-containing plasmid, pMP3, and its disrupted derivative, $\mathrm{p} S P R 3 \triangle \mathrm{Cla}$-LEU2, have been described previously (Kao et al. 1989). YCp50-SPR3 contained the wild-type SPR3 gene cloned as a $5.8 \mathrm{~kb} H$ indIII fragment into YCp50. YCp50-SPR3 was kindly provided by Gautam Kao. pspr6:lacZ contains a protein fusion which places the potential $S P R 6$ open reading frame upstream of an allele of lac $Z$ which lacks its own transcriptional and translational start signals. The $3.0 \mathrm{~kb} \mathrm{lac} Z$ fragment from pMC1871 (Casadaban et al. 1983) was cloned as a SmaI-SalI fragment into the corresponding unique restriction sites of pRI1. This placed the E. coli gene in the predicted $S P R 6$ open reading frame. This $s p r 6: l a c Z$ hybrid was then transferred to pRS315 (Sikorski and Hieter 1989) using the $P s t$ I and $S a l$ I sites which flank the spr6:lacZ fusion. The latter vector is maintained in single copy in $S$. cerevisiae cells by the activities of the CEN6 and $A R S H 4$ elements present on the vector and is selected in yeast by the presence of the LEU2 gene.

$\beta$-galactosidase assays. Strains to be assayed for lac $Z$ expression from the SPR6 fusion were transformed freshly with pspr6:lacZ and were maintained on minimal medium. These were transferred to the selective PSP medium and grown for $18-24 \mathrm{~h}$ prior to a shift to sporulation medium as described above. Extracts were prepared from $5.0 \mathrm{ml}$ of culture (approximately $10^{8}$ cells) by the method of Rose and Botstein (1983). Cells were pelleted by centrifugation (10000 $\mathrm{g}$ in plastic centrifuge tubes) and resuspended in $0.3 \mathrm{ml}$ of yeast breaking buffer $(80 \mathrm{mM}$ Tris $\mathrm{pH} 7.2,4 \% \mathrm{v} / \mathrm{v}$ glycerol, $1 \mathrm{mM}$ dithiothreitol). Glass beads $(0.45 \mathrm{~mm}$; Thomas Scientific, Swedesboro, $\mathrm{NJ}$ ) were added to the level of the original meniscus, and the suspension was placed at $-70^{\circ} \mathrm{C}$ for at least $1 \mathrm{~h}$. The cells were then thawed and $6.5 \mu \mathrm{l}$ of a $40 \mathrm{mM}$ PMSF (phenylmethylsulfonylfluoride) solution was added. The cells were broken by vortexing the suspension at the highest setting of the instrument. Three 1 min bursts, with 3-5 min cooling on ice between bursts, were usually adequate to break $>95 \%$ of the cells or spores. An additional $0.35 \mathrm{ml}$ of yeast breaking buffer was added to the extracts after breakage. Activity was assayed using $0.150 \mathrm{ml}$ of the extracts as described by Miller (1972) except that $Z$ buffer was supplemented with $0.025 \%$ SDS (sodium dodecyl sulfate) as in Ruby et al. (1983). Activity was defined as $\mathrm{nMol}$ ONPG hydrolyzed per min per mg protein in the extracts; $1 \mathrm{nMol}$ of product was assumed to have an absorbance of 0.00265 at $420 \mathrm{~nm}$ in a final assay volume of $1.7 \mathrm{ml}$. Protein concentration was determined by the method of Bradford (1976) using the commercially available reagent (Bio-Rad) as recommended by the supplier. Bovine $\operatorname{IgG}$ was used as a standard. 
A

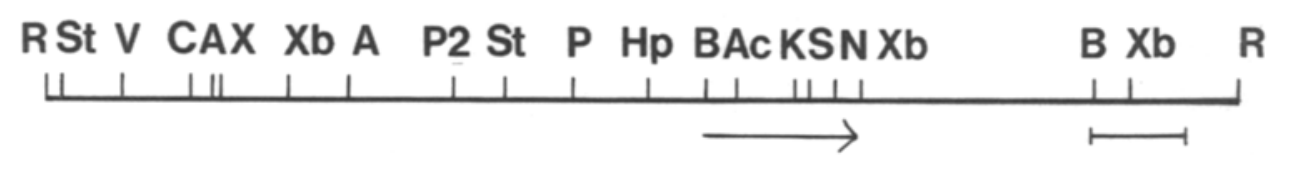

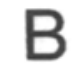

STAINED

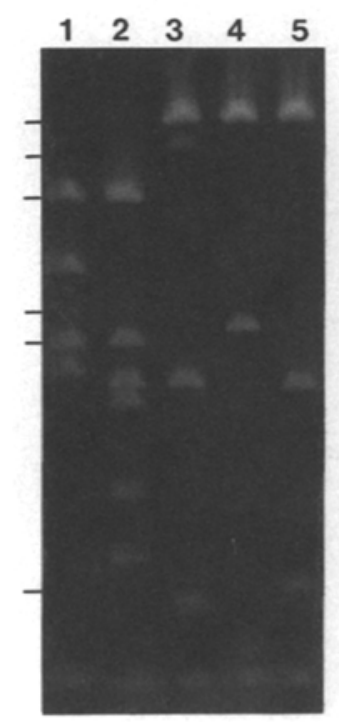

9 HOUR

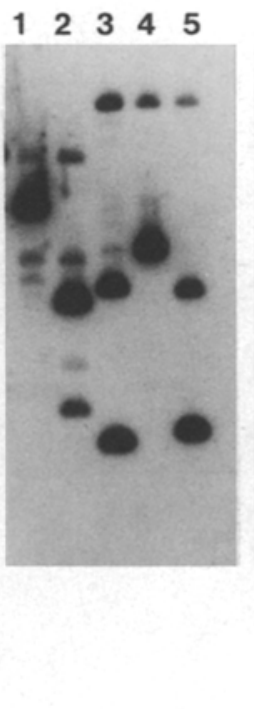

2 HOUR

$\begin{array}{lllll}1 & 2 & 3 & 4 & 5\end{array}$
Fig. 1A-C. Localization of the SPR6 transcription unit. Panel A the $6.4 \mathrm{~kb}$ insert in pRI1 was mapped with the restriction enzymes EcoRI (R), SstI (St), EcoRV (V), ClaI (C), AvaI $(A)$, XhoI $(X), X b a \mathrm{I}$ $(X b)$, PvuII (P2), PstI (P), HpaII (Hp), BstEII (B), AccI (Ac), KpnI $(K), S m a I(S)$ and $X m n I(N)$. The arrow below the figure indicates the direction of transcription. The bar indicates a size scale of $500 \mathrm{bp}$. Not all sites for $A c c \mathrm{I}$ are shown. Panel $B$ restriction fragments from pRI1 were fractionated by agarose gel electrophoresis and stained (left) or blotted to nitrocellulose (middle and right). The blots were hybridized to ${ }^{32} \mathrm{P} \mathrm{c}$-DNA from cells that had been exposed to sporulation medium for 9 (middle) or $2 \mathrm{~h}$ (right). The lines at sides of the left and right panels indicate the final positions of migration of standard marker fragments after electrophoresis. Those present in the region shown in the photograph were (top to

\section{Purification and manipulation of nucleic acids:}

(1) DNA. Yeast genomic DNA was isolated from small $(5-40 \mathrm{ml})$ cultures as described by Sherman et al. (1981). E. coli plasmid DNA and M13 RF (replicative form) DNAs were prepared using the "rapid boiling" method of Holmes and Quigley (1981) or by $\mathrm{CsCl}$ density gradient centrifugation as in Davis et al. (1980). Singlestranded M13 DNA was isolated from cleared supernatants of phage-infected cultures grown on $\mathrm{YT}$ medium as described by Messing (1983).

(2) RNA. Total RNA was isolated from yeast cells by the method of Kaback and Feldberg (1985) using guanidium isothiocyanate and $\beta$-mercaptoethanol as deaturants. For some experiments, poly $A^{+}$RNA was isolated by the method of Aviv and Leder (1972) as described by Maniatis et al. (1982). RNA for use in preparation of cDNA was purified by chromatography on Sephadex G-50 as described by St. John and Davis (1979).

(3) Nucleic acid hybridizations. Probes for Northern and Southern blots were usually DNAs which had been labeled with ${ }^{32} \mathrm{P}$ by nick-

\section{C}

\section{mp18 mp19}

$\begin{array}{llll}1 & 2 & 1 & 2\end{array}$

bottom) $9.4 \mathrm{~kb}, 6.6 \mathrm{~kb}, 2.3 \mathrm{~kb}, 2.0 \mathrm{~kb}$, and $0.5 \mathrm{~kb}$. Lanes $1,2,3,4$ and 5 contained restriction fragments produced from pRI1 by the

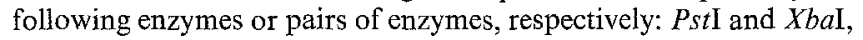
AccI, KpnI and BstEII, BstEII, SmaI and BstEII. Panel C $10 \mu \mathrm{g}$ of total RNA from cells that had been exposed to sporulation medium for 2 (lanes 1 ) and 9 (lanes 2 ) h was fractionated by agarose gel electrophoresis. The position of the SPR6 transcript was visualized using a two-step hybridization procedure as described by Breter et al. (1983). The blots were hybridized to an unlabeled probe which consisted of the BstEII-KpnI fragment internal to the coding region of SPR6 cloned into M13mp18 and M13mp19. Hybridization of the blot to the first probe was visualized by a second hybridization to M13 RF that had been labeled by nick translation

translation using the method of Rigby et al. (1977) as described in Maniatis (1982), or ${ }^{32} \mathrm{P}-\mathrm{cDNAs}$ prepared as described previously (Clancy et al. 1983). The direction of transcription of SPR6 was determined by the method of Reed (Breter et al. 1983) using the $0.5 \mathrm{~kb}$ BstEII-KpnI fragment internal to the gene, cloned into M13mp1 8 and M13-mp19. Northern blots were prepared by the method of Thomas (1983) except that DMSO (dimethylsulfoxide) was omitted from the denaturation solution. Alternatively, RNA was denatured and fractionated by electrophoresis in the presence of formaldehyde as described by Yarger et al. (1986). Southern blots (Southern 1975) were prepared as described previously (Clancy et al. 1983). Hybridization of blots to ${ }^{32} \mathrm{P}$-cDNA, nick-translated DNA or single-stranded probes was performed at $42^{\circ} \mathrm{C}$ as described by Engel and Dodgson (1981).

(4) Manipulation of nucleic acids. Restriction enzyme digestions, kinase reactions and ligations were performed as recommended by the suppliers of these enzymes. DNA fragments for cloning were isolated by electroelution (Maniatis et al. 1982) from $0.8-1.4 \%$ agarose gels that were poured and run in Tris-acetate buffer, or by 


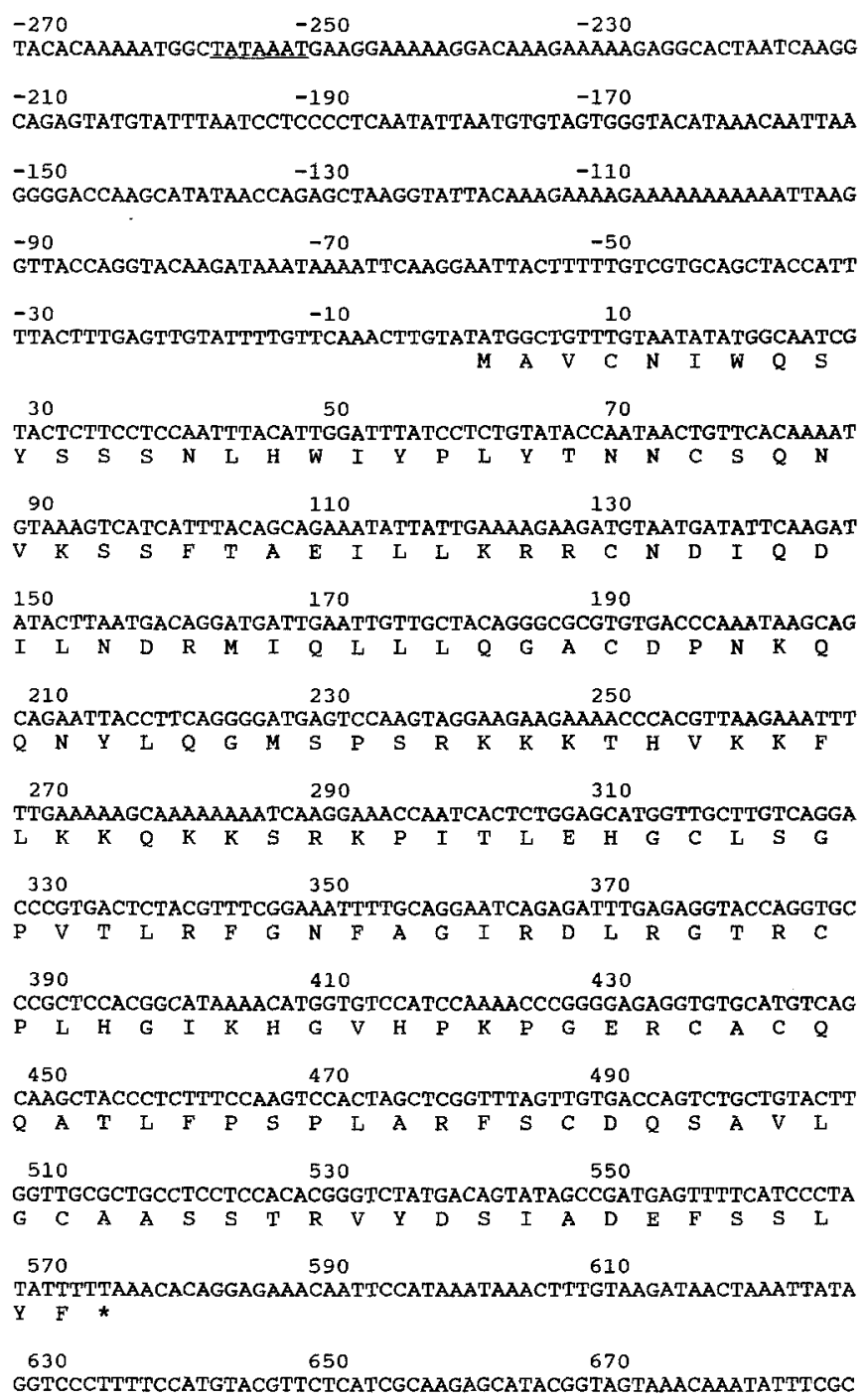

Fig. 2. Sequence analysis of SPR6. The region surrounding the sporulation-specific transcription unit was sequenced as described in Materials and methods, and is shown using the proposed translation initiation site as the +1 nucleotide. The predicted amino acid sequence is shown using the single letter code

extraction from low melting temperature agarose (LMT; Seaplaque FMC BioProducts, Rockland, Me.) as recommended by the supplier. Preparation of DNAs for sequencing was accomplished by cloning restriction fragments into the RF of M13-mp18 and M13-mp19, and by constructing unidirectional deletions. A $2.4 \mathrm{~kb} P_{s t} \mathrm{I}-X b a \mathrm{I}$ fragment from pRI1, spanning the SPR6 gene, was cloned into M13-mp18 and M13-mp19. Nested deletions were constructed using the CYCLONE kit from International Biotechnologies Inc. Single-stranded template DNA was hybridized to a 22-base oligomer (for EcoRI) or a 29-base oligomer (for HindIII), digested with the appropriate restriction enzyme and incubated with T4 polymerase. The resulting molecules were tailed with dGTP or dCTP, reannealed to the original oligomer, and ligated. Clones containing deletions spanning the region of interest were sequenced using the dideoxynucleotide chain termination method (Sanger et al. 1977). Sequencing reactions utilized the Klenow fragment of DNA polymerase I or Sequenase (Tabor and Richardson 1987) using reagent kits as directed by the suppliers (Bethesda Research Laboratories and United States Biochemicals, respectively). Fragments sequenced included a 474 nucleotide BstEII-KpnI fragment, a 716 nucleotide $P_{s t}$ I-Bst EII fragment, a 649 nucleotide $A c c$ I fragment and a 75 nucleotide $S m a I-K p n I$ fragment, cloned with M13 in both orientations. Deleted molecules included endpoints at nucleotides $1676,1556,1237,1160$, and 1050 relative to the Pst I site to the left of the SPR6 gene as shown in Fig. 1.

\section{Results}

\section{Characterization of the SPR6 transcription unit}

$S P R 6$ was originally identified in a screen for $\lambda$ clones which contained highly expressed genes whose transcripts are specific to sporulating cells. The $6.4 \mathrm{~kb} E c o$ RI fragment containing the sporulation-specific gene in one such $\lambda$ isolate was subcloned into pBR322 and mapped with restriction enzymes (pRI1, Fig. 1, panel A). This gene was designated SPR6, based on the hybridization pattern of the original $\lambda$ clone to others isolated by differential screening (Holaway et al. 1985). To locate the SPR6 transcription unit within this DNA, we hybridized ${ }^{32} \mathrm{P}-\mathrm{cDNA}$ prepared from cells that had been incubated in sporulation medium for 2 or $9 \mathrm{~h}$ (Fig. 1, panel B) to restriction fragments of $\mathrm{pRI1}$. These results enabled us to identify those restriction fragments that contained portions of the SPR6 transcription unit as shown.

To determine the direction of transcription of SPR6, we hybridized strand-specific probes to RNA that had been prepared from sporulating cells. The probes were made from a $0.5 \mathrm{~kb}$ Bst EII-KpnI fragment of the SPR6 transcription unit that had been cloned into M13-mp18 and M13-mp19. The single-stranded virion DNAs were used to probe transcription in the SPR6 region. In these experiments, the unlabeled single-stranded phage DNA was hybridized to RNA that had been extracted from cells at early and late stages in the sprorulation process. Hybridization was visualized by the use of a second probe (M13 RF form) according to the method of Reed (Breter et al. 1983). The results showed that SPR6 is transcribed in the rightward direction as the insert is shown (Fig. 1, panel $\mathrm{C}$; arrow in panel A).

\section{Sequence analysis}

To locate the structural features that are expected to occur within functional $S$. cerevisiae transcription units, we determined the nucleotide sequence of the transcribed and flanking regions of the gene (Fig. 2). The transcribed region contains a 573 nucleotide open reading frame whose location is consistent with the expected position of the protein coding region. This open reading frame could encode a polypeptide 191 amino acids in length with a molecular mass of $21527 \mathrm{Da}$. The predicted protein has a high proportion of serine and threonine residues ( 28 of the 191 amino acids). These are found throughout the potential coding region, with a cluster near the amino terminus. The predicted polypeptide is quite hydrophilic, with an overall composition of $36 \%$ polar residues. A particularly basic region occurs between residues 80 to 100; this contains 11 lysine and two arginine residues. Searches of the Genbank and EMBL databases did not reveal any significant homologies between SPR6 and protein or nucleic acid sequences of known function. 
The 300 nucleotide region immediately upstream of the presumed initiating ATG contains several TATA-like sequences. The closest in sequence to the accepted consensus (Sentenac and Hall 1982) begins at -259 with respect to the ATG which marks the beginning of the long open reding frame (TATAAA). Similar sequences lie at -204 (TATTTAAAT), -185 (TATTAAT), -141 (TATAAC) and -124 (TAAATAAA). There are also seven examples of sequences that conform to preferred transcription initiation sites within the region spanning -60 to -240 . These include two TCG/AA elements and five of sequence RRYRR (reviewed by Guarente 1987). We have also obtained evidence for transcripts originating in this region, using primer extension analysis (data not shown).

\section{Translational competence of SPR6 $m R N A$}

To determine whether SPR6 encodes RNAs that are translated in vivo, we constructed a translational fusion between the SPR6 coding region and a lac $Z$ reporter from $E$. coli. A $3.0 \mathrm{~kb}$ SmaI-SalI fragment from pMC1871 (Casadaban et al. 1983) was used to replace a $3.0 \mathrm{~kb}$ SmaI-Sall fragment from pRI1. This placed lac $Z$ in the expected reading frame, near the $3^{\prime}$ end of SPR6. This construction was then transferred to the shuttle vector pRS315 (Sikorski and Hieter 1989) and introduced into the diploid yeast strain, GKY5 and its isogenic haploids, GK25 and GK31.

Assays of extracts from sporulating cells carrying this fusion showed that SPR6-directed $\beta$-galactosidase expression occurred preferentially during sporulation, as expected from the behavior of the corresponding transcript. Essentially no activity (less than 0.01 specific activity) was detected in YEPA or PSP-grown cells. By 9 after the shift to sporulation medium, activity was easily detectable, although extremely low (specific activities between 0.1 and 0.5 in different experiments). This level of expression was very low relative to that which has been observed for some other sporulation-specific fusion proteins ( $S P R 1$ and $S P R 3$ ) but well above the limits of detection of this assay. In addition, control haploid strains, that contained the spr $6:$ lac $Z$ fusion but could not sporulate, did not express any activity above the basal levels detected in YEPD or PSP. We conclude from these experiments that at least a subset of the SPR6 transcripts that are produced are translated during sporulation, but possibly at very low efficiency.

\section{Disruption of SPR6}

To determine whether SPR6, like the other late genes, is inessential for sporulation, we examined the sporulation capability of strains that lacked SPR6 activity. We constructed two alleles of SPR6 in which portions of the open reading frame had been replaced by the wild-type HIS3 gene. The first construction (pSG3) lacked the 75 bp KpnI-SmaI fragment near the $3^{\prime}$ end of the gene, and the second (pLK 3 ) lacked a $2.1 \mathrm{kp} \mathrm{Bst} \mathrm{EII} \mathrm{fragment}$
Table 2. Sporulation of strains homozygous for combinations of $S P R$ gene disruptions

\begin{tabular}{|c|c|c|c|}
\hline Strain & Disrupted gene & $\begin{array}{l}\% \text { Tetra- } \\
\text { nucleate } \\
\text { (\% of wild- } \\
\text { type) }\end{array}$ & $\begin{array}{l}\text { \% Sporu- } \\
\text { lation }{ }^{6} \\
\text { (\% of wild- } \\
\text { type) }\end{array}$ \\
\hline DK337 & none & $68.3(100)$ & $63.9(100)$ \\
\hline YLK1396 & none & $68.8(100)$ & $65.8(100)$ \\
\hline YLK16-9a & $S P R 1, S P R 6$ & $75.0(110)$ & $63.1 \quad(98.7)$ \\
\hline YLK1335-3 & $S P R 1, S P R 3$ & $62.1 \quad(90.1)$ & $47.7 \quad(74.6)$ \\
\hline YLK36-1a & $S P R 3, S P R 6$ & $63.4 \quad(92.8)$ & $51.6 \quad(80.8)$ \\
\hline YLK9820 & SPR1, SPR3, SPR6 & $52.7 \quad(83.7)$ & $35.6 \quad(55.8)$ \\
\hline YLK984 & SPR1, SPR3, SPR6 & $57.2 \quad(77.2)$ & $43.1 \quad(67.4)$ \\
\hline
\end{tabular}

a Determined by DAPI staining following $72 \mathrm{~h}$ incubation in sporulation medium. At least 200 cells were examined for each determination shown. Results shown are for a single experiment in which all cultures were grown and sporulated simultaneously

b Cells were sporulated for $72 \mathrm{~h}$ following pregrowth in YEPD and YEPA. At least 500 cells were counted for each determination shown. All results shown are from cells which had been cultured and sporulated simultaneously

spanning the entire SPR6 coding region. These alleles were used to replace the corresponding wild-type sequences in a diploid strain, DK337. This manipulation resulted in strains that were heterozygous for the spr6:HIS3 alleles. All disruptions were confirmed by Southern blotting. During the course of these experiments, we never observed any bands other than those expected if SPR6 were a single copy gene.

Homozygous diploids were formed by sporulation of the heterozygote and reconstruction of the diploid by mating His ${ }^{+}$segregants, or by transformation with $\mathrm{HO}$. Exposure of these diploids to sporulation medium revealed that SPR6 is inessential for sporulation. In two typical experiments, in which over 400 cells of each genotype were counted, the disrupted strains sporulated to 49.6 and $50.7 \%$ after $48 \mathrm{~h}$ of incubation in sporulation medium, as compared to 48.0 and 49.3 for the wild-type controls. Analysis of these frequencies by the Chi-squared test for homogeneity (see Conover 1981) revealed that there are no statistically significant differences between them. Thus, strains homozygous for the defective alleles sporulated at levels which were indistinguishable from those of closely related wild-type controls.

The null spr6: HIS3 allele also had no effect on spore viability. Dissection of 58 complete tetrads from a homozygous spr6: HIS 3 strain estimated an overall viability of $83.2 \%$. By comparison, $80.5 \%$ of spores from DK 337 were viable (50 tetrads). Analysis of segregants from a spr6: $H I S 3 / S P R 6$ heterozygote gave similar results; three of the six inviable spores from 20 tetrads were inferred to be $\mathrm{His}^{+}$, whereas the remaining three were $\mathrm{His}^{-}$. We conclude that lack of SPR6 activity had no effect on spore viability or germination.

\section{Multiple disruptions}

Our earlier observations support the idea that some of the $S P R$ genes contribute to the sporulation capability of 
Table 3. Complementation of sporulation defect of disrupted strains

\begin{tabular}{|c|c|c|}
\hline Strain & Gene disruption in strain & $\begin{array}{l}\% \text { Sporulation }{ }^{a} \\
(\% \text { of wild-type) }\end{array}$ \\
\hline \multicolumn{3}{|l|}{ Complementation by. $S P R 3$ : } \\
\hline YLK1396 & Heterozygous for spr3:LEU2 spr $1: L E U 2$ and spr6:HIS3 & $58.0(100)$ \\
\hline YLK1396+YCp50-SPR3 & Same as above & $57.1(98.4)$ \\
\hline YLK9820 & spr3:LEU2 spr1:LEU2 spr6:HIS3 & $46.1 \quad(79.5)$ \\
\hline YLK $984+Y C p 50-S P R 3$ & Same as above & $62.6(108)$ \\
\hline \multicolumn{3}{|l|}{ Complementation by SPR6: } \\
\hline YLK1396 & Heterozygous for spr3:LEU2 spr1:LEU2 and spr6:HIS3 & $64.6(100)$ \\
\hline YLK1396+YCp50-SPR6 & Same as above & $63.5(98.3)$ \\
\hline YLK984 + YCp50-SPR6 & Same as above & $59.9(92.7)$ \\
\hline
\end{tabular}

a Over 600 cells were counted for each determination shown. Cells were sporulated for $72 \mathrm{~h}$ after pregrowth in YEPD and YEPA. Sporulation medium was supplemented with tryptophan, adenine and uracil

yeast cells without being essential to the process. Strains which lack SPR3 activity, due to a $L E U 2$ insertion in the gene, exhibit a slight, but statistically significant, reduction in sporulation efficiency which is evident only after analysis of a very large number of cells (Kao et al. 1989). More subtle defects associated with other $S P R$ disruptions could thus escape detection entirely. We, therefore, reasoned that the small contributions of each $S P R$ gene might be revealed as a more pronounced phenotype in strains which lacked several $S P R$ functions simultaneously. This could occur as an additive effect resulting from the removal of several helpful functions.

Table 2 shows the results of an experiment in which the sporulation capabilities of strains which lacked the activity of two or more $S P R$ functions were examined. In all cases, multiply-disrupted strains exhibited slightly reduced sporulation relative to the controls; this was especially evident when the strains lacked $S P R 3$ activity. The most pronounced effect was obtained with strains which were simultaneously defective for SPR1, SPR3 and $S P R 6$; these strains sporulated to approximately $60 \%$ of the wild-type levels after $72 \mathrm{~h}$ of incubation in sporulation medium (Table 2). As for the singly disrupted strains, spores from triple disruptants were as viable as the wild-type ( $>80 \%$ in both cases).

We have examined the statistical significance of the data in Table 2, using a Chi-squared test as above. By this analysis, the sporulation frequencies of the two wild-type strains were indistinguishable from that of the doubly mutant spr1 : LEU2 spr6: HIS3 strain. By contrast, chance alone is highly unlikely to be the sole source of the variation between the other multiple mutants as compared to wild-type (>99.9\%). Because these strains are not completely isogenic, we cannot conclude with certainty that the observed effects are exclusively the result of the $S P R$ mutations. Nonetheless, we find this result highly suggestive.
Complementation of the sporulation defect of multiply disrupted strains

The result of a more compelling experiment are shown in Table 3. We expected that if the modest sporulation defect associated with the triply-disrupted strain were the result of diminished $S P R$ gene activity, then this defect could be complemented by the introduction of the corresponding wild-type genes on plasmids. To examine this question, we asked whether two plasmids, YCp50-SPR3 and YCp50-SPR6, could restore wild-type levels of sporulation to multiply-mutant strains.

The results of two such experiments are shown in Table 3. The wild-type strain, YLK1396, which was heterozygous for the SPR1,SPR3 and SPR6 disruptions, sporulated equally well in the presence and absence of the YCp50-SPR3 and YCp50-SPR6 plasmids. By contrast, the multiply-mutant strains sporulated consistently better when provided with either SPR3 or SPR6 activity. These levels were restored to $90-100 \%$ of wild-type levels in the presence of SPR-complementing activity, compared to $75-85 \%$ in its absence.

These data were also subjected to Chi-squared analysis. In all cases, the defects associated with the multiple disruptions were significant at the $99 \%$ level, or greater, when compared to the YLK1396 control. In addition, the levels of sporulation attained in the presence of the complementing SPR3 and SPR6 plasmids were significantly higher than in their absence (at the $>97.5 \%$, or greater, level in all cases, $>99 \%$ in most). We conclude that the $S P R$ genes retain some function during sporulation, even though they are inessential to the process.

\section{Mapping SPR6}

To determine the map position of SPR6, we hybridized pRI1 to a preparation of yeast chromosomes that had 
Table 4. Position of SPR6 relative to markers on chromosome V

\begin{tabular}{lllll}
\hline & PD $^{\mathrm{a}}$ & NPD & TT & Conclusion \\
\hline MET6-ILV1 & 74 & 0 & 29 & $14.1 \mathrm{cM}$ \\
MET6-spr6:HIS3 & 74 & 0 & 30 & $14.4 \mathrm{cM}$ \\
spr6:HIS3:LLV1 & 45 & 0 & 58 & $28.2 \mathrm{cM}$ \\
\hline
\end{tabular}

a PD, NPD, and TT refer to parental ditype, non-parental ditype and tetratype asci, respectively

been fractionated by alternating field electrophoresis. A single band was observed at the position corresponding to chromosome V. Table 4 shows the results of a cross between a strain which contained an allele of SPR6 that had been marked with HIS3, and one which carried met6, ura3 and ilv1. Both strains were his 3 at the normal locus to allow SPR6 - HIS3 to be scored using histidine prototrophy as a marker. The resulting diploid was also heterozygous for the trp1 CEN-linked marker. Analysis of segregants from this cross allowed SPR6 to be placed approximately $14.4 \mathrm{cM}$ centromere-distal to met6. spr6: HIS3 was unlinked to CEN (data not shown).

More detailed analysis of the data from this experiment confirmed the order of genes given; in all cases the expected rearrangements of outside markers were observed in tetratype asci. It was somewhat surprising, however, that no DCO (double crossover) asci of any kind were obtained (Table 4 and data not shown). This apparent level of interference is not unusual (Mortimer et al. 1989); numerous experiments that have examined genetic regions in the $20-35 \mathrm{cM}$ length range have yielded no NPD tetrads.

\section{Discussion}

Progress through sporulation in the yeast Saccharomyces cerevisiae is marked by changes in the abundance of numerous RNAs. Some of these correspond to genes whose functions are crucial to the sporulation process, including IME1, IME2, SPO11, SPO12, SPO13 and others (Kassir et al. 1988; Smith and Mitchell 1989; Atcheson et al. 1987; Wang et al. 1987). Among the most abundant transcripts present in sporulating cells, however, are many which serve no obvious functional roles; null alleles of many sporulation-specific genes support levels of sporulation which are indistinguishable from isogenic wildtype controls.

In an effort to understand whether these inessential transcription units confer any function or advantage to the yeast, we have examined the structure of one of the late genes. We show that SPR6 contains several features that are characteristic of $S$. cerevisiae transcription units and that the gene is capable of encoding a protein 191 amino acids in length. The 300 nucleotide region upstream of the SPR6 open reading frame contains several TATA-like sequences, including one (at -259) that is an exact match to the accepted consensus.

Before we could infer any potential function for SPR6, it was necessary to determine whether SPR6 mRNA is competent for translation. We show that lac $Z$ fused in the predicted SPR6 reading frame was expressed in a sporulation-dependent manner, but at low levels. Thus, we believe that the predicted protein is expressed by yeast during sporulation. Similar results have previously been obtained for SPR3 (Holaway et al. 1987; Kao et al. 1989) and $S P R 1$ (D. Primerano, unpublished); SPS1, SPS2, SPS4, SGA1 and SPS100 also contain long open reading frames.

We have also examined the effects of SPR6 null mutations on the ability of diploid $S$. cerevisiae cells to sporulate. As for several other late genes that have been examined, SPR6 activity is inessential for sporulation and the production of viable ascospores; null alleles allow wildtype levels of sporulation and the resulting ascospores are as viable as the controls. In addition, the cells appeared normal by DAPI staining and the kinetics of meiosis were the same in the mutant and wild-type backgrounds (data not shown).

It remains possible, however, that SPR6 activity might be needed for sporulation under conditions other than those usually employed in the laboratory. Our experiments were all performed at $30^{\circ} \mathrm{C}$ and followed a growth regimen that was developed to optimize, rather than limit, the sporulation efficiencies of normal strains. Sporulation at extreme temperatures, or under other adverse conditions, might be more sensitive to the genetic defects we have constructed if, indeed, the role of these gene is to enhance essential functions.

We have not examined the mutant strains for more subtle defects in ascospore structure, acquisition of thermal or ethanol tolerance, or for the lack of any other spore function except viability. Thus, it is possible that a more detailed analysis might reveal a discrete phenotype for the spr6:HIS3 mutation that would not have emerged from the study described here. Indeed, experiments in other laboratories have shown that defects in other inessential sporulation-specific genes can lead to delayed appearance of thermal and ether tolerance (Law and Segall 1988; D. Primerano and P. T. Magee, personal communication).

As an alternative route to discerning a role for $S P R 6$, and perhaps the other late genes, we constructed strains that lacked all combinations of SPR1, SPR3 and SPR6 activities. In most cases, these mutations led to significant and reproducible decreases in sporulation efficiency. This was most evident in strains which lacked all three of the $S P R$ genes examined. The defect associated with the triply-mutant strains could be complemented by either the SPR 3 or SPR6 genes on plasmids, suggesting that the lack of these gene activities was responsible for the limitation of sporulation that we observed. We conclude that the $S P R$ genes have retained some functional role in the sporulation process.

These results are somewhat difficult to interpret, since these three genes share no sequence homology that would suggest a common or reiterated function for their respective products. The SPR6 sequence is unrelated to that of SPR1 (D. Primerano et al., submitted), SPR3 (M. Clancy and M. Bhattacharyya, unpublished), or to any other proteins in the Genbank or EMBL databases. The only 
common feature of these three genes is their coordinate expression at the time of meiosis I during sporulation. On the other hand, it is necessary to suggest some functional overlap among the products of these genes, to explain the ability of both SPR3 and SPR6 to complement the defect associated with the triply-mutant strains. We suggest, therefore, that the $S P R$ genes contribute to the sporulation process by increasing its efficiency.

It is well-documented that wild-type yeast strains vary enormously in their ability to sporulate, although the genetic bases for these differences are unclear. Many laboratory strains achieve only $10-15 \%$ sporulation after extended exposure to sporulation medium, whereas others form $90 \%$ or more ascospores after only $12-16 \mathrm{~h}$. These properties can, in some cases, be transmitted through genetic crosses (Esposito and Klapholz 1981). These differences depend on a multitude of metabolic functions, especially those needed for utilization of acetate and endogenous nitrogen stores. Such nutritional information is utilized by the cell at several decision-making steps in the sporulation process. These include the initiation of the process upon starvation, the initiation of meiotic divisions, and during spore formation (reviewed in Esposito and Klapholz 1981). Thus, inessential functions could impinge on the central, essential, ones by influencing these decision-making steps.

Acknowledgements. The authors would like to thank Drs. P. T. Magee, Mike Fennewald, Dwight Nissley, Gautam Kao and James Yarger for helpful discussions. We also gratefully acknowledge Dr. David Kaback, Dr. Ira Herskowitz, the Yeast Genetics Stock Center and the organizers of the Cold Spring Harbor Yeast Course for strains and plasmids. We are especially grateful to Kay Finn for providing excellent technical assistance and to Carmelo Milano for his help in constructing the restriction and transcript maps of SPR6. Sequence analysis was accomplished using the Intelligenetics Bionet Resource. This work was supported by NSF grants DCB-8308606, DCB-8615886 and DMB-8908445 to M.J.C. and by a Sigma-Xi Grant-in-Aid to L.A.K.

\section{References}

Atecheson C, DiDominico B, Frackman S, Esposito RE (1987) Proc Natl Acad Sci USA 84:8035-8039

Aviv H, Leder P (1972) Proc Natl Acad Sci USA 69:1408-1412

Boeke JD, Garfinkel DJ, Styles CA, Fink JR (1985) Cell 40:491500

Bradford M (1976) Anal Biochem 72:248-254

Breter H-J, Ferguson J, Peterson TA, Reed SI (1983) Mol Cell Biol 3: $881-891$

Broach JR, Strathern JN, Hicks JB (1979) Gene 8:121-133

Casabadan MJ, Martinez-Arias A, Shapira SK, Chou J (1983) Methods Enzymol 100:293-308

Clancy MJ, Buten-Magee B, Straight DJ, Kennedy A, Partridge RM, Magee PT (1983) Proc Natl Acad Sci USA 80:3000-3004

Coleman KG, Steensma HY, Kaback DB, Pringle JR (1986) Mol Cell Biol 6:4516-4525

Conover WJ (1981) Practical Nonparametric Statistics, 2nd edn. John Wiley and Sons, New York, pp 143-153

Davis RW, Botstein D, Roth JR (1980) A manual for genetic engineering: Advanced bacterial genetics. Cold Spring Harbor Laboratory, Cold Spring Harbor, New York

Engel JD, Dodgson JB (1981) Proc Natl Acad Sci USA 78: 28562860
Esposito RE, Klapholz S (1981) In: Stathern JN, Jones EW, Broach JR (eds) Molecular biology of the yeast Sacchromyces: Life cycle and inheritance. Cold Spring Harbor Laboratory, Cold Spring Harbor, New York, pp 211-287

Garber AT, Segall J (1986) Mol Cell Biol 6:4478-4485

Goebl M, Petes TD (1986) Cell 46:983-992

Gottlin-Ninfa E, Kaback DB (1986) Mol Cell Biol 6:2185-2197

Guarante L (1987) Annu Rev Genet 21:425-452

Hanahan D (1983) J Mol Biol 166:557-580

Holaway BL, Lehman DJ, Primerano DA, Magee PT, Clancy MJ (1985) Curr Genet 10:163-169

Holaway BL, Kao G, Finn MC, Clancy MJ (1987) Mol Gen Gent 210:449-459

Holmes D, Quigley M (1981) Anal Biochem 114: 193-197

Ito H, Fukuda Y, Murata K, Kimura A (1983) J Bacteriol 153: 163 168

Kaback DB, Oeller PW, Steensma HY, Hirschman J, Ruezinsky D, Coleman KG, Pringle JR (1984) Genetics 108:67-90

Kaback DB, Feldberg FR (1985) Mol Cell Biol 5:751-761

Kao G, Mannix DG, Holaway BL, Finn MC, Bonny AE, Clancy MJ (1989) Mol Gen Genet 215:490-500

Kassir Y, Granot D, Simchen G (1988) Cell: 853-862

Law DS, Segall J (1988) Mol Cell Biol 8:912-922

Lindquist S, Craig EA (1988) Annu Review Genet 22:631-677

Maniatis T, Fritsch EF, Sambrook J (1982) Molecular cloning: A laboratory manual. Cold Spring Harbor Laboratory, Cold Spring Harbor, New York

Messing J (1983) Methods Enzymol 101:20-78

Miller JH (1972) Experiments in molecular genetics. Cold Spring Harbor Laboratory, Cold Spring Harbor, New York

Mortimer RK, Schild D, Contopoulou CR, Kans JA (1989) Yeast 5: $321-403$

Osley MA, Hereford LM (1981) Cell 24:377-384

Percival-Smith A, Segall J (1984) Mol Cell Biol 4:142-150

Percival-Smith A, Segall J (1986) Mol Cell Biol 6:2443-2457

Rigby PW, Dieckmann M, Rhodes C, Berg P (1977) J Mol Biol 113:237-251

Rose M, Botstein D (1983) Methods Enzymol 101:167-180

Rothstein R (1983) Methods Enzymol 101:202-211

Ruby S, Szostak JW, Murray AW (1983) Methods Enzymol 101:253-269

Russell PW, Jensen R, Zoller MJ, Burke J, Errede B, Smith M, Herskowitz I (1986) Mol Cell Biol 6:4281-4294

Sanger F, Nicklen S, Coulson AR (1977) Proc Natl Acad Sci USA 74: $5463-5467$

Sentenac A, Hall B (1982) In: Strathern JN, Jones EW, Broach JR (eds) Molecular Biology of the yeast Saccharomyces. Metabolism and gene expression. Cold Spring Harbor Laboratory, Cold Spring Harbor, New York, pp 561-606

Sherman F, Fink GR, Hicks JB (1981) Methods in yeast genetics. Cold Spring Harbor Laboratory, Cold Spring Harbor, New York

Sikorski RS, Hieter P (1989) Genetics 122:19-27

Smith HE, Mitchell AP (1989) Mol Cell Biol 9:2142-2152

Southern EM (1975) J Mol Biol 98:503-517

Steensma HY, Crowley JC, Kaback DB (1987) Mol Cell Biol 7:410-419

St. John TP, Davis RW (1979) Cell 16:443-452

Tabor S, Richardson CC (1987) Proc Natl Acad Sci USA 84: 4767 4771

Thomas PS (1983) Methods Enzymol 100:255-266

Wang H-T, Frackman S, Kowalisyn J, Esposito RE, Elder R (1987) Mol Cell Biol 7:1425-1435

Williamson DH, Fennel DJ (1975) Methods Cell Biol 12:335-351

Yamashita I, Fukui S (1985) Mol Cell Biol 5:3069-3073

Yarger JG, Armilei G, Gorman MC (1986) Mol Cell Biol 6: 10951101

Communicated by G. Simchen 